\title{
Erratum to: Integrated population models reveal local weather conditions are the key drivers of population dynamics in an aerial insectivore
}

\author{
Mitch D. Weegman 1,2,7 • Todd W. Arnold ${ }^{1}$ Russell D. Dawson ${ }^{3} \cdot$ \\ David W. Winkler ${ }^{4,5} \cdot$ Robert G. Clark ${ }^{6}$
}

Published online: 18 August 2017

(C) Springer-Verlag GmbH Germany 2017

\section{Erratum to: Oecologia}

DOI 10.1007/s00442-017-3890-8

Unfortunately, the equation was incorrectly published in the original article and the same is corrected here in this erratum. The original article was corrected.

The correct $N$ equations should be:

$$
\begin{aligned}
& N_{\text {yearling }, t+1}=\left(N_{\text {yearling }, t}+N_{\mathrm{ad}, t}+N_{\mathrm{imm}, t}\right) \phi_{\mathrm{juv}, t} f_{t} \\
& N_{\mathrm{ad}, t+1}=\left(N_{\text {yearling }, t}+N_{\mathrm{ad}, t}+N_{\mathrm{imm}, t}\right) \phi_{\mathrm{ad}, t} \\
& N_{\mathrm{imm}, t+1}=\left(N_{\text {yearling }, t}+N_{\mathrm{ad}, t}+N_{\mathrm{imm}, t}\right) \omega_{t}
\end{aligned}
$$

The online version of the original article can be found under doi:10.1007/s00442-017-3890-8.

Mitch D. Weegman

weegmanm@missouri.edu

1 Department of Fisheries, Wildlife and Conservation Biology,

University of Minnesota, St. Paul, MN 55108, USA

2 Department of Biology, University of Saskatchewan, Saskatoon, SK S7N 5E2, Canada

3 Ecosystem Science and Management Program, University of Northern British Columbia, Prince George, BC V2N 4Z9, Canada

4 Department of Ecology and Evolutionary Biology, Cornell University, Ithaca, NY 14853, USA

5 Cornell Lab of Ornithology, Cornell University, Ithaca, NY 14850, USA

6 Prairie and Northern Wildlife Research Centre, Environment and Climate Change Canada, Saskatoon, SK S7N 0X4, Canada

7 Present Address: School of Natural Resources, University of Missouri, Columbia, MO 65211, USA 